\title{
Algorithm for cavo-tricuspid isthmus flutter on surface ECGs: the ACTIONS study.
}

\author{
Daniel Frisch \\ Cardiology, Thomas Jefferson University, Philadelphia, PA, United States \\ Eitan Frankel \\ Internal Medicine, Thomas Jefferson University Hospital, Philadelphia, PA, United States \\ Deanna Gill \\ Internal Medicine, Emory University Hospital, Atlanta, GA, United States \\ Jad Al Danaf \\ Division of Cardiovascular Medicine, University of Utah Health, Salt Lake City, UT, United States
}

Follow this and additional works at: https://jdc.jefferson.edu/cardiologyfp

Let us the Cardiology Commons
Let us how how access to this document benefits you

\section{Recommended Citation}

Frisch, Daniel; Frankel, Eitan; Gill, Deanna; and Danaf, Jad Al, "Algorithm for cavo-tricuspid isthmus flutter on surface ECGs: the ACTIONS study." (2021). Division of Cardiology Faculty Papers. Paper 71.

https://jdc.jefferson.edu/cardiologyfp/71

This Article is brought to you for free and open access by the Jefferson Digital Commons. The Jefferson Digital Commons is a service of Thomas Jefferson University's Center for Teaching and Learning (CTL). The Commons is a showcase for Jefferson books and journals, peer-reviewed scholarly publications, unique historical collections from the University archives, and teaching tools. The Jefferson Digital Commons allows researchers and interested readers anywhere in the world to learn about and keep up to date with Jefferson scholarship. This article has been accepted for inclusion in Division of Cardiology Faculty Papers by an authorized administrator of the Jefferson Digital Commons. For more information, please contact: JeffersonDigitalCommons@jefferson.edu. 


\title{
openheart Algorithm for cavo-tricuspid isthmus flutter on surface ECGs: the ACTIONS study
}

\author{
Daniel R Frisch (D) , ${ }^{1}$ Eitan Frankel, ${ }^{2}$ Deanna Gill (D) ${ }^{3}$ Jad Al Danaf ${ }^{4}$
}

To cite: Frisch DR, Frankel E, Gill D, et al. Algorithm for cavotricuspid isthmus flutter on surface ECGs: the ACTIONS study. Open Heart 2021;8:e001431. doi:10.1136/ openhrt-2020-001431

Received 26 August 2020 Revised 19 November 2020 Accepted 1 December 2020

\section{Check for updates}

(c) Author(s) (or their employer(s)) 2021. Re-use permitted under CC BY-NC. No commercial re-use. See rights and permissions. Published by BMJ.

${ }^{1}$ Cardiology, Thomas Jefferson University, Philadelphia, Pennsylvania, USA

${ }^{2}$ Internal Medicine, Thomas Jefferson University Hospital, Philadelphia, Pennsylvania, USA ${ }^{3}$ Internal Medicine, Emory University Hospital, Atlanta, Georgia, USA

${ }^{4}$ Division of Cardiovascular Medicine, University of Utah Health, Salt Lake City, Utah, USA

Correspondence to Dr Deanna Gill; dxg082@ jefferson.edu

\section{ABSTRACT}

Objective Cavo-tricuspid isthmus atrial flutter (CTI-AFL) is an important arrhythmia to recognise because there is a highly effective and relatively low-risk ablation strategy. However, clinical experience has demonstrated that providers often have difficulty distinguishing AFL from atrial fibrillation.

Methods We developed a novel ECG-based three-step algorithm to identify CTI-AFL based on established CTI flutter characteristics and verified on consecutive ablation cases of typical flutter, atypical flutter and atrial fibrillation. The algorithm assesses V1/inferior lead F-wave concordance, consistency of P-wave morphology and the presence of isoelectric intervals in the inferior leads. In this observation study, the algorithm was validated on a cohort of 50 second-year medical students. Students were paired in a control and experimental group, and each pair received 10 randomly selected ECGs (from a pool of 50 intracardiac electrogram-proven CTI-AFL and $50 \mathrm{AF}$ or atypical AFL cases). The experimental group received a cover sheet with the CTI algorithm, and the control group received no additional guidance.

Results There was a statistically significant difference in the mean number of correctly identified ECGs among the students in the experimental and control groups (8.12 vs $5.68, p<0.001)$. Students who used the algorithm correctly identified 2.44 more ECGs as being CTI-AFL or not CTI-AFL. Using the electrophysiology study as the gold standard, the algorithm had an accuracy of $81 \%$, sensitivity of $81 \%$, specificity of $82 \%$, positive predictive value of $78 \%$ and negative predictive value of $84 \%$ in identifying CTI-AFL.

Conclusion We developed a three-step ECG algorithm that provides a simple, sensitive, specific and accurate tool to identify CTI-AFL.

\section{INTRODUCTION}

Atrial flutter (AFL) is a relatively common arrhythmia with an estimated annual incidence of 200000 cases in the USA. ${ }^{1}$ In the 1970s, AFL was defined as a continuously waving pattern on ECG without an isoelectric baseline in at least one lead. ${ }^{2}$ It was further classified as type I or type II based on F-wave rate and the ability to be entrained during an invasive electrophysiology study. ${ }^{3}{ }^{4}$ Since these initial descriptions, there have been

\section{Key questions}

What is already known about this subject?

- Cavo-tricuspid isthmus atrial flutter (CTI-AFL) is an important arrhythmia to recognise because there is a highly effective and relatively low-risk ablation strategy.

- The characteristics of CTI flutter on ECG including V1/inferior lead F-wave concordance, consistency of P-wave morphology and the presence of isoelectric intervals in the inferior leads have been well established.

- Ablation of CTI-AFL is successful in up to $97 \%$ of cases.

What does this study add?

- This study showed that a novel three-step algorithm based on known CTI-AFL ECG characteristics outperformed basic ECG knowledge in identifying CTI-AFL.

How might this impact on clinical practice?

- More patients with CTI-AFL will be identified and, by extension, considered for specific therapy for CTIAFL (ie, ablation).

numerous observations regarding the electrophysiological mechanisms underlying AFL. In the early 2000 s, the cardiology community adopted a revised definition of AFL based on atrial location and arrhythmia mechanism. ${ }^{5}$ Generally, AFL can be classified as cavotricuspid isthmus dependent (CTI-AFL), which accounts for more than $90 \%$ of AFLs, or atypical when the mechanism does not include the CTI (figure 1).

CTI-AFL is an important arrhythmia to recognise because there is a highly effective and relatively low-risk ablation strategy, which often relieves symptoms and may reduce adverse consequences such as tachycardiainduced cardiomyopathy. ${ }^{6}$ However, clinical experience has demonstrated that providers often have difficulty distinguishing AFL from atrial fibrillation. It is relevant to make this distinction because these two arrhythmias often have different initial management 


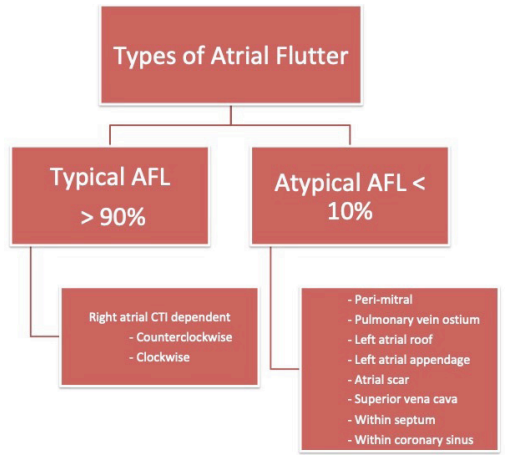

Figure 1 Types of AFL including typical AFL and atypical AFL, along with their occurrence rates. AFL, atrial flutter; CTI, cavo-tricuspid isthmus.

strategies. Patients with atrial fibrillation may benefit from an initial strategy of electrical cardioversion, antiarrhythmic therapy or an attempt at rate control. Patients with AFL should often be referred to an electrophysiologist to consider ablation as the first-line therapy. Despite numerous descriptions of CTI-AFL patterns, there is no specific algorithmic approach to recognise CTI-AFL on a surface ECG. Using characteristic patterns of flutter described in the literature, we developed the CTI algorithm to identify CTI-AFL. This algorithm was then validated using a series of ablation-proven cases.

\section{METHODS}

\section{Patient and public involvement}

Patients were not involved in this study. Students were involved in this study after the development of the algorithm and collection of deidentified sample ECGs. Students were recruited through campus-wide emails on a voluntary basis. Recruitment emails informed the students of the 30-min or less time requirement.

\section{Development of the algorithm}

A literature review was performed to identify common features of CTI-AFL on ECG and to search for any existing algorithms. While there were some attempts to use surface ECG to identify specific electrophysiological mechanisms of AFL (eg, upper loop re-entry), these discussions were often too complex for our goal of helping clinicians identify CTI-AFL. ${ }^{7-9}$ We chose to focus on descriptions of typical AFL and typical reverse AFL. Typical AFL (counterclockwise) has a sawtooth pattern, negative flutter waves in the inferior leads and V6, and a positive flutter wave in lead V1; the polarity of these waves is opposite for typical reverse (clockwise) AFL. ${ }^{2}$ While these two classic patterns are familiar for experienced clinicians to recognise on most ECGs, they are specific and not sensitive in defining CTI-AFL. ${ }^{10}$ In addition, they do not always allow differentiation of coarse atrial fibrillation from AFL. There is no simple algorithm to help clinicians identify possible CTI-AFL. Based on this information gap, we developed a novel ECG-based three-step algorithm to identify CTIAFL. The CTI algorithm assesses V1/inferior lead F-wave concordance, consistency of the P-wave morphology and the presence of isoelectric intervals in the inferior leads (figures 2 and 3).

\section{Cohort selection and algorithm validation}

After the algorithm was developed, we selected 50 consecutive typical AFL and 50 consecutive atrial fibrillation or atypical AFL ablation cases to validate the algorithm. Between May and August 2016, 50 second-year medical students at our institution were enrolled into a prospective cohort for the validation study and sequentially placed into a control or experimental group. The goal of 50 students was set as recruitment became challenging. Students in each group were paired, and each pair received a packet of 10 randomly selected ECGs (from the 100 cases). Students were asked to determine whether each ECG was consistent or inconsistent with CTI-AFL. The experimental group received a cover sheet with the CTI algorithm. The control group received no additional guidance and was instructed not to consult additional resources.

\section{Outcome measures and statistical analysis}

The primary outcome was whether the CTI algorithm improved the students' ability to accurately define CTIAFL. The secondary outcome was the specificity of the algorithm in identifying CTI-AFL. A paired t-test was used to analyse whether the algorithm improved the students' ability to accurately define CTI-AFL. A Bayesian statistical analysis was used with standard definitions of sensitivity, specificity, positive predictive value and negative predictive value to identify the testing characteristics of the algorithm.

\section{RESULTS}

In total, the 50 students interpreted 500 ECGs (from a pool of 100 ECGs) with a $100 \%$ completion rate. Using a paired t-test, there was a statistically significant difference in the mean number of correctly identified ECGs among the students in the experimental and control groups (8.12 vs 5.68, $\mathrm{p}<0.001$; table 1 ). Students who used the algorithm correctly identified 2.44 more ECGs as being CTI-AFL. Using intracardiac electrograms and response to ablation as the gold standard, the algorithm had an accuracy of $81 \%$, sensitivity of $81 \%$, specificity of $82 \%$, positive predictive value of $78 \%$ and negative predictive value of $84 \%$ in identifying CTI-AFL (table 2).

\section{DISCUSSION}

The major finding of this study is that an algorithm for recognising CTI-AFL based on known ECG characteristics of CTI-AFL outperformed basic ECG knowledge in identifying CTI-AFL. The algorithm is a simple, threequestion process that asks yes/no questions. It had a sensitivity of $81 \%$, a specificity of $82 \%$, a positive predictive value of $78 \%$ and a negative predictive value of $84 \%$. Using the algorithm, a group of medical students were 


\begin{tabular}{|c|l|}
\hline \multicolumn{2}{|c|}{ CTI Algorithm } \\
\hline C & $\begin{array}{l}\text { Concordance Test. Is the P-wave vector (direction) in the inferior leads (II, } \\
\text { III, or aVF) opposite (discordant to) that of V1? Look for the longest gap } \\
\text { between QRS complexes to find P waves that are not overlapped by a T wave } \\
\text { or a QRS complex. }\end{array}$ \\
\hline T & $\begin{array}{l}\text { Timing. Is the morphology of the P-waves uniform across the ECG (any single } \\
\text { lead)? If you cannot easily identify P waves because of overlap by the T wave } \\
\text { and if the QRS complexes are present at regular intervals (i.e. 2:1 conduction, } \\
\text { especially if the QRS rate is 150 BPM), CTI flutter is likely ("yes" answer). }\end{array}$ \\
\hline I & $\begin{array}{l}\text { Isoelectric Intervals. Are isoelectric intervals (flat lines between P waves) } \\
\text { absent in the inferior leads (leads II, III, or aVF)? CTI flutter should not have } \\
\text { an isoelectric segment in leads II, III, and aVF. }\end{array}$ \\
\hline If all Yes & CTI flutter diagnosed \\
\hline If any No & CTI flutter excluded \\
\hline
\end{tabular}

Figure 2 The CTI algorithm as it appeared when distributed to the medical students in the experimental group. BPM, beats per minute; CTI, cavo-tricuspid isthmus.

able to accurately identify $24 \%$ more ECGs as being consistent with CTI-AFL. Regarding the non-CTI AFL ECGs that were identified as CTI, they did appear to have regular flutter leads, but on closer inspection they did not meet at least one of the other two criteria for typical flutter in the algorithm (ie, V1/inferior lead discordance and/or isoelectric intervals). Conversely, the origins of AFL that students falsely identified as typical AFL were
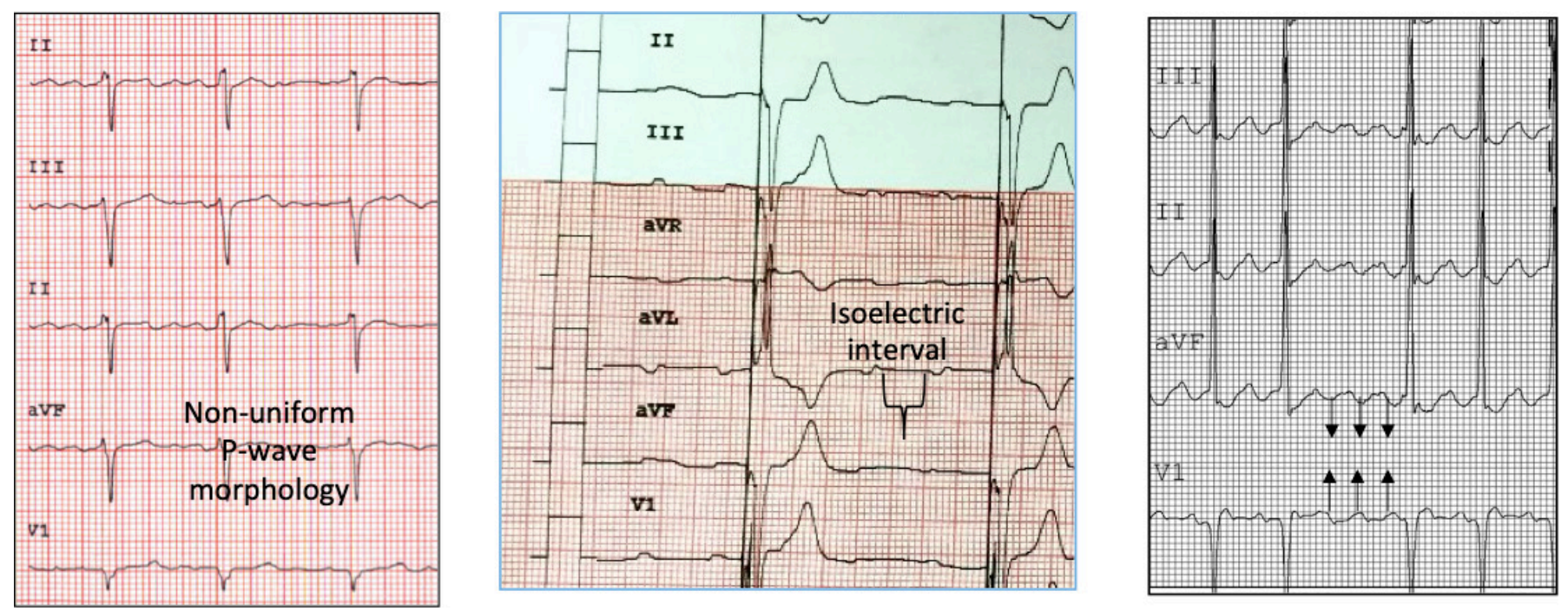

Figure 3 Parts of the algorithm demonstrated on ECGs. CTI-AFL, cavo-tricuspid isthmus atrial flutter. The left panel shows non-uniform morphology of the $\mathrm{P}$ wave and thereby all three criteria are not met thus, this is not CTI-AFL. The middle panel shows an isoelectric interval in the inferior leads and thereby all three criteria are not met thus this is not CTI-AFI. The right panel shows that all three criteria are met thereby, identifying the EGG as CTI-AFL. 
Table 1 Impact of the CTI algorithm on students' ability to identify CTI-AFL

Impact of the CTI algorithm on students' ability to identify CTI-AFL

\begin{tabular}{llllll}
\hline & $\mathbf{n}$ & $\begin{array}{l}\text { Number correct } \\
\text { (mean) }\end{array}$ & SD & 95\% Cl & \\
\hline No algorithm & 25 & 5.68 & 1.11 & 5.22 to 6.12 & \\
Algorithm & 25 & 8.12 & 1.09 & 7.67 to 8.57 & $p<0.001$ \\
\hline
\end{tabular}

AFL, atrial flutter; CTI, cavo-tricuspid isthmus.

various, including right inferior pulmonary vein, right superior pulmonary vein, left inferior pulmonary vein, septal, mitral, roof and the left atrial appendage.

The implication of this study's findings is that more patients with CTI-AFL will be identified and, by extension, considered for specific therapy for CTI-AFL (ie, ablation). This is relevant because ablation of CTI-AFL is successful in up to $97 \%$ of the cases. ${ }^{11}{ }^{12}$ In addition, ablation is associated with low complication rates, ranging from $0.5 \%$ to $2.6 \%$, so it is well tolerated by the majority of patients. ${ }^{61112}$ By allowing clinicians to more accurately distinguish CTI-AFL from atrial fibrillation, patients with AFL can receive definitive therapy with fewer ineffective attempts at rate control.

Our study has limitations. While the target audience for the algorithm is clinicians who frequently order ECGs and may be the first providers to identify an atrial arrhythmia, the algorithm was validated among medical students. However, medical students were intentionally selected as they represent a large cohort with relatively uniform and basic ECG skills. Thus, their responses were more likely reflective of the algorithm rather than ECG skills based on exposure to ECGs, individual study and experience. In the future, testing could be done in a physician population to ensure that the testing characteristics of the algorithm are similar. Another potential limitation of the study is that the positive predictive value and negative predictive values of the algorithm were around $80 \%$. These numbers are still valuable as a tool to help increase awareness and identification of CTI-AFL. These positive and negative predictive values likely reflect the inherent limitations in the interpretation of surface ECGs. One of the explanations for the lack of a higher specificity may derive from the observation that some non-CTI flutters mimic CTI-AFL on ECG and that some diagnoses can only be made with intracardiac recordings. Furthermore, the ability to observe flutter waves without T-wave overlap was impossible for some of the cases. While the mechanistic distinction between CTI-AFL and non-CTI AFL is critical

\section{Table 2 Validation of the CTI algorithm}

\section{EP study}

\begin{tabular}{llc}
\cline { 2 - 3 } Student & CTI & Not CTI \\
\hline CTI & 91 & 25 \\
Not CTI & 22 & 112 \\
\hline
\end{tabular}

CTI, cavo-tricuspid isthmus; EP, electrophysiology . to make during an ablation procedure, we were willing to accept false positives in our algorithm if it would increase the number of patients referred for potentially curative, ablative therapy.

In conclusion, we developed a three-step ECG algorithm based on known ECG characteristics of CTI-AFL that provides a simple, sensitive, specific and accurate tool to identify CTI-AFL. Early identification of this arrhythmia may allow for more rapid management, reduction in comorbidities and improvement in patient outcomes.

Contributors All authors had access to the data and a role in designing the study, recruiting patients and writing the manuscript.

Funding The authors have not declared a specific grant for this research from any funding agency in the public, commercial or not-for-profit sectors.

Competing interests None declared.

Patient consent for publication Not required.

Ethics approval The study complies with the Declaration of Helsinki. The study contained human participants including medical students who were surveyed on a voluntary basis. The human subject involvement was deemed to be minimal risk by Thomas Jefferon's Internal Review Board and did not warrant further ethical approval.

Provenance and peer review Not commissioned; externally peer reviewed.

Data availability statement All data relevant to the study are included in the article or uploaded as supplementary information. Patient data are deidentified and obtained from ablation records of Dr Daniel Frish (author).

Open access This is an open access article distributed in accordance with the Creative Commons Attribution Non Commercial (CC BY-NC 4.0) license, which permits others to distribute, remix, adapt, build upon this work non-commercially, and license their derivative works on different terms, provided the original work is properly cited, appropriate credit is given, any changes made indicated, and the use is non-commercial. See: http://creativecommons.org/licenses/by-nc/4.0/.

\section{ORCID iDs}

Daniel R Frisch http://orcid.org/0000-0002-7645-6405

Deanna Gill http://orcid.org/0000-0002-7808-3067

\section{REFERENCES}

1 Granada J, Uribe W, Chyou PH, et al. Incidence and predictors of atrial flutter in the general population. J Am Coll Cardiol 2000;36:2242-6.

2 Saoudi N, Cosío F, Waldo A, et al. A classification of atrial flutter and regular atrial tachycardia according to electrophysiological mechanisms and anatomical bases; a statement from a joint expert group from the Working group of arrhythmias of the European Society of cardiology and the North American Society of pacing and electrophysiology. Eur Heart J 2001;22:1162-82.

3 Scheinman MM, Yang Y. Atrial flutter: historical notes--part 1. Pacing Clin Electrophysiol 2004;27:379-81.

4 Scheinman MM, Yang Y, Cheng J. Atrial flutter: Part II nomenclature. Pacing Clin Electrophysiol 2004;27:504-6.

5 Inama G, Pedrinazzi C, Durin O, et al. Usefulness and limitations of the surface electrocardiogram in the classification of right and left atrial flutter. J Cardiovasc Med 2006;7:381-7. 
6 Clementy N, Desprets L, Pierre B, et al. Outcomes after ablation for typical atrial flutter (from the Loire Valley Atrial Fibrillation Project). Am J Cardiol 2014;114:1361-7.

7 Bochoeyer A, Yang Y, Cheng J, et al. Surface electrocardiographic characteristics of right and left atrial flutter. Circulation 2003;108:60-6.

8 Yuniadi Y, Tai C-T, Lee K-T, et al. A new electrocardiographic algorithm to differentiate upper loop re-entry from reverse typical atrial flutter. J Am Coll Cardiol 2005;46:524-8.

9 Medi C, Kalman JM. Prediction of the atrial flutter circuit location from the surface electrocardiogram. Europace 2008;10:786-96.
10 Milliez P, Richardson AW, Obioha-Ngwu O, et al. Variable electrocardiographic characteristics of isthmus-dependent atrial flutter. J Am Coll Cardiol 2002;40:1125-32.

11 Pérez FJ, Schubert CM, Parvez B, et al. Long-term outcomes after catheter ablation of cavo-tricuspid isthmus dependent atrial flutter: a meta-analysis. Circ Arrhythm Electrophysiol 2009;2:393-401.

12 Spector P, Reynolds MR, Calkins H, et al. Meta-analysis of ablation of atrial flutter and supraventricular tachycardia. Am J Cardiol 2009;104:671-7. 